\title{
Las panorámicas de Málaga dibujadas por Francis Carter en 1772-1773
}

\author{
Luis Ruiz Padrón y Antonio Gámiz Gordo \\ Universidad de Sevilla \\ paradeisos@hotmail.com; antoniogg@us.es
}

RESUMEN: Las tres vistas panorámicas de la ciudad de Málaga que Francis Carter dibujó en 1772-1773 y publicó en 1777 constituyen una valiosa fuente documental que permite conocer su entorno paisajístico, hoy transformado por crecimientos urbanos posteriores. Tras considerar su contexto general se aporta un análisis inédito, localizando sus puntos de vista y ángulos visuales comprendidos, para poner en valor la configuración de la ciudad representada, sus murallas, perfiles e hitos arquitectónicos en el paisaje malagueño de finales del XVIII. Aunque su valor artístico no es destacable, se corrobora su gran interés como testimonio de su época, considerando algunas vistas históricas de otros autores como referente comparativo, cotejando su fiabilidad y la precisión de los abundantes pormenores dibujados.

PALABRAS CLAVE: Carter; Málaga; Dibujo; Grabado; Panorámica; Ciudad; Paisaje.

\section{The Panoramic View of Malaga Drawn by Francis Carter in 1772-1773}

ABSTRACT: The three panoramic views of the city of Malaga that Francis Carter drew in 1772-1773 and published in 1777 are a valuable documentary source that shows its surrounding landscape, today transformed by later urban growths. After considering its general context, an unpublished analysis is provided, pinpointing its vantage points and visual angles, in order to assess the layout of the city represented in the drawings, its walls, skyline and architectural landmarks in the landscape of Malaga in the late 18th century. Although their value as artistic pieces is unremarkable, they are a great testimonial value of the period, to use with views from other artists as a comparative reference, thus checking the reliability and accuracy of the abundant details drawn.

KEYWORDS: Carter; Malaga; Drawing; Engraving; Panoramic; City; Landscape.

Recibido: 26 de febrero de 2018 / Aceptado: 24 de abril de 2018.

\section{Consideraciones generales}

Las vistas de ciudades son documentos de excepcional valor para comprender la evolución de los paisajes urbanos históricos. En ellas reside la percepción real que se tenía de las ciudades en el pasado y gran parte de su identidad presente. Además de los restos arqueológicos y de las edificaciones de otros tiempos, los únicos vestigios que nos han quedado de dichos atributos visuales del pasado y de las alteraciones del paisaje urbano son los dibujos o imágenes de la época y, en menor medida, sus descripciones literarias, hasta la llegada de la fotografía como registro documental a mediados del siglo XIX (Gámiz, 2011: 78).

Dichos testimonios resultan especialmente valiosos en aquellos casos en los que las transformaciones fueron más profundas, como ocurrió en Málaga. La ciudad medieval y renacentista sufrió tales cambios durante los siglos XIX y XX que hoy, a excepción de sus hitos principales, resulta difícilmente reconocible. Afortunadamente, el paisaje urbano histórico de Málaga cuenta con numerosas y relevantes fuentes gráficas que permiten reconstruir visualmente su evolución desde el siglo XVI (Ruiz, 2016).

Cómo citar este artículo: RUIZ PADRÓN, Luis y GÁMIZ GORDO, Antonio: “Las panorámicas de Málaga dibujadas por Francis Carter en 1772-1773», Boletín de Arte-UMA, n. ${ }^{\circ}$ 39, Departamento de Historia del Arte, Universidad de Málaga, 2018, pp. 205-216, ISSN: 0211-8483, DOI: http://dx.doi.org/10.24310/BoLArte.2018.v0i39.4203 
Aunque muchas de estas imágenes son bastante conocidas, hasta ahora sus contenidos han sido poco estudiados en relación con su contexto urbano y paisajístico, valorando la precisión o fiabilidad de la información gráfica que aportan. Dicho asunto constituye el objetivo central de la presente investigación sobre las vistas de Carter.

Debe considerarse que algunas vistas históricas han sido objeto de mayor atención por la aparente cientificidad o rigor del procedimiento utilizado en su elaboración o por la reconocida personalidad de su autor como artista. Sin embargo han pasado más desapercibidas otras menos atractivas desde un punto de vista compositivo o artístico. Según Marías, son estas precisamente las que nos interesan más como historiadores de «imágenes de ciudades» (2002: 100).

En este sentido, las tres vistas panorámicas de Málaga realizadas por Francis Carter constituyen una aportación muy relevante. Sus obvias limitaciones artísticas como dibujante hacen que sus imágenes palidezcan ante la maestría desplegada por otros autores como Anton van den Wyngaerde (Gámiz y Ruiz, 2018) o David Roberts (Ruiz, 2016), dos casos muy singulares que evidenciaron una clara voluntad de aprehender el paisaje urbano malagueño en toda su riqueza y complejidad panorámica. Sin embargo, la exhaustiva recopilación de datos contenidos en las vistas de Carter, no solo en cuanto a hitos arquitectónicos y topografía, sino también sobre aspectos referentes a cultivos, costumbres, tráfico marítimo u otros asuntos, las hacen merecedoras de una mirada más atenta. Al igual que Wyngaerde o Roberts, Carter sería consciente de que para explicar de forma amplia una ciudad, esta debe ser vista desde diferentes ángulos. Solo la combinación de esas miradas cruzadas permite obtener una visión de conjunto, y la orografía malagueña es especialmente propicia para ello.

\section{Francis Carter y sus imágenes sobre Málaga}

Tras el estancamiento de la ciudad en el siglo XVII, los inicios del siglo XVIII supusieron un importante revulsivo: la Guerra de Sucesión y la llegada de los Borbones al trono facilitó la difusión de las nuevas ideas de la llustración en el llamado "Siglo de las Luces». Durante dicha guerra se produjo la conquista de Gibraltar por los ingleses en 1704, y ello motivaría una reactivación de las obras portuarias en
Málaga, lo cual vino a coincidir con la creación del Cuerpo de Ingenieros del Ejército y una mejora generalizada de las infraestructuras en todo el territorio. Diversas actuaciones alteraron profundamente la faz de la ciudad malagueña, profusamente documentada en distintos proyectos, planos o dibujos que ilustran propuestas transformadoras de aquel paisaje.

El caso de Francis Carter (1736?-1783) resulta bastante singular porque no fue un viajero propiamente dicho, ya que residió en Málaga al menos durante cinco años, según se indica en una nota incluida en uno de sus dibujos, después comentada. Las razones de su prolongada estancia en nuestro país son aún una incógnita (Garvayo, 2003: 307) (Olmedo, 1980:39). Sobre dicha cuestión el propio Carter se expresaba en términos poco explícitos: «he conocido España desde mi infancia, y, desde 1753 a 1773, toda mi vida -excepto cinco años pasados en Francia- ha transcurrido en Andalucía y reino de Granada». A continuación añadía: «Durante tan larga ausencia busqué consuelo en el estudio de los lugares donde me tocó residir» (Carter, 1981: 1).

Desde Málaga partió definitivamente hacia Inglaterra el 3 de julio de 1773, según se indica en las páginas finales del libro resultante de su estancia, publicado en 1777 (con una segunda edición en 1780) bajo el título A Journey from Gibraltar to Malaga, with a View of that Garrison and its Environs; a Particular Account of the Towns in the Hoya of Malaga; the Ancient and Natural History of those Cities, of the Coast between them, and of the Mountains of Ronda. Illustrated with the Medals of each Municipal Town; and a chart, perspectives and drawings, taken in the year 1772.

La obra está articulada en dos tomos, divididos a su vez en dos libros cada uno. Los tres primeros libros están dedicados a la descripción de los pueblos y paisajes recorridos en el viaje al que alude el título, que duró solamente cinco días. El cuarto está dedicado a la ciudad de Málaga y constituye el núcleo temático de su obra.

Se incluyen vistas sobre las ruinas de Cartaya, Gibraltar, Ronda, Ardales, Marbella o Cártama, además de tres panorámicas y otras vistas de Málaga. Aunque no tienen especial valor artístico, dichas vistas son de gran interés por encontrarse entre las más tempranas representaciones conocidas de dichas poblaciones. Su inclusión se justificó en el propio prólogo con las siguientes palabras: 
1. Francis Carter (dib., 1773) Basire (grab., 1776): North West View of Malaga seen from a hill opposite the Trinity with the Agua-Medina flowing (detalle). Autorretrato

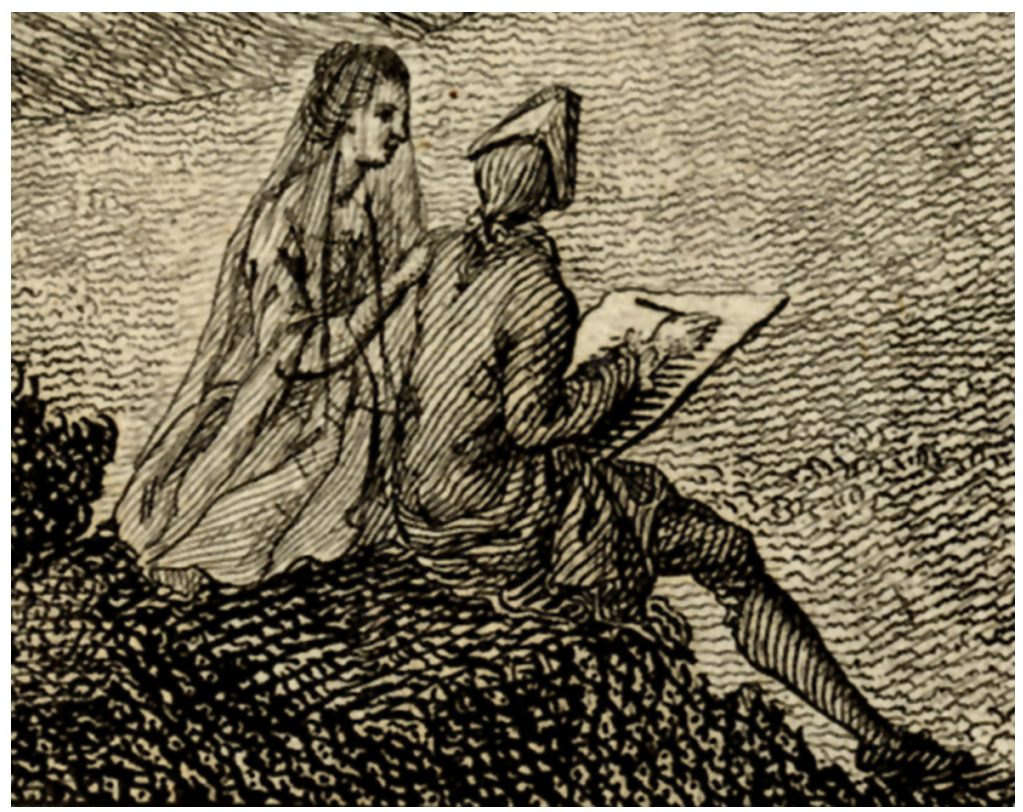

He grabado un mapa de la región que describo, que dibujé yo mismo sobre un plano totalmente nuevo; y, sensible a su utilidad, ventajas y, casi me atrevo a decir, absoluta necesidad de vistas y perspectivas para completar e ilustrar mejor la descripción de los siete a veinte dibujos que hice de cada pueblo que visité, he elegido y reproducido trece en una escala apropiada a la edición para que formen parte integral de ésta (1981: 1).

Entre ellas destacan las vistas dedicadas a Málaga, especialmente las tres panorámicas insertadas a modo de desplegable en el libro, que resultan de gran interés por la información gráfica que acumularon sobre la ciudad y su paisaje, sus perfiles y su inserción en el territorio circundante. Carter se refería a ellas con las siguientes palabras:

Mi estancia aquí durante nueve meses me ha dado oportunidad de hacer tres dibujos grandes de la ciudad, como también vistas de sus puertas árabes y de su Catedral, que con los ya mencionados, voy a reducir a la escala apropiada a esta obra y a publicar; para que todo sea completo, las voy a dibujar yo mismo, y serán terminadas bajo mi control con el mayor cuidado, no como la mayoría de los viajeros actuales, que se contentan con un dibujo en esbozo, porque no tienen gana ni paciencia para acabarlo en el mismo sitio, engañando así al mundo con vistas que nunca existieron sino en la imaginación del grabador (1981: 228).

Esta declaración de intenciones queda subrayada por el hecho de que en una de las vistas se representó a sí mismo como dibujante, con los útiles de dibujo y en plena faena [1]. Otros dibujantes habían efectuado dicha práctica; son bien conocidas las vistas en las que Wyngaerde también lo hizo. Si bien Carter carecía de la maestría para el dibujo que poseían ciertos viajeros, dicha carencia quedó compensada por la meticulosidad y dedicación con la que acometió su tarea gráfica y por su clara voluntad de abarcar amplias panorámicas de la ciudad con puntos de vista complementarios, añadiendo además ilustraciones sobre otros motivos arquitectónicos.

\section{Los puntos de vista y encuadres de las panorámicas}

Los «tres dibujos grandes de la ciudad» a los que alude el texto del propio Carter son las tres panorámicas fechadas en 1772 y 1773, grabadas por Basire en 1776. Las dos primeras abarcan la ciudad completa desde el Sur y desde el Noroeste. En el primer caso, el punto de vista está en el extremo del muelle nuevo, incluyendo un alzado de la ciudad 


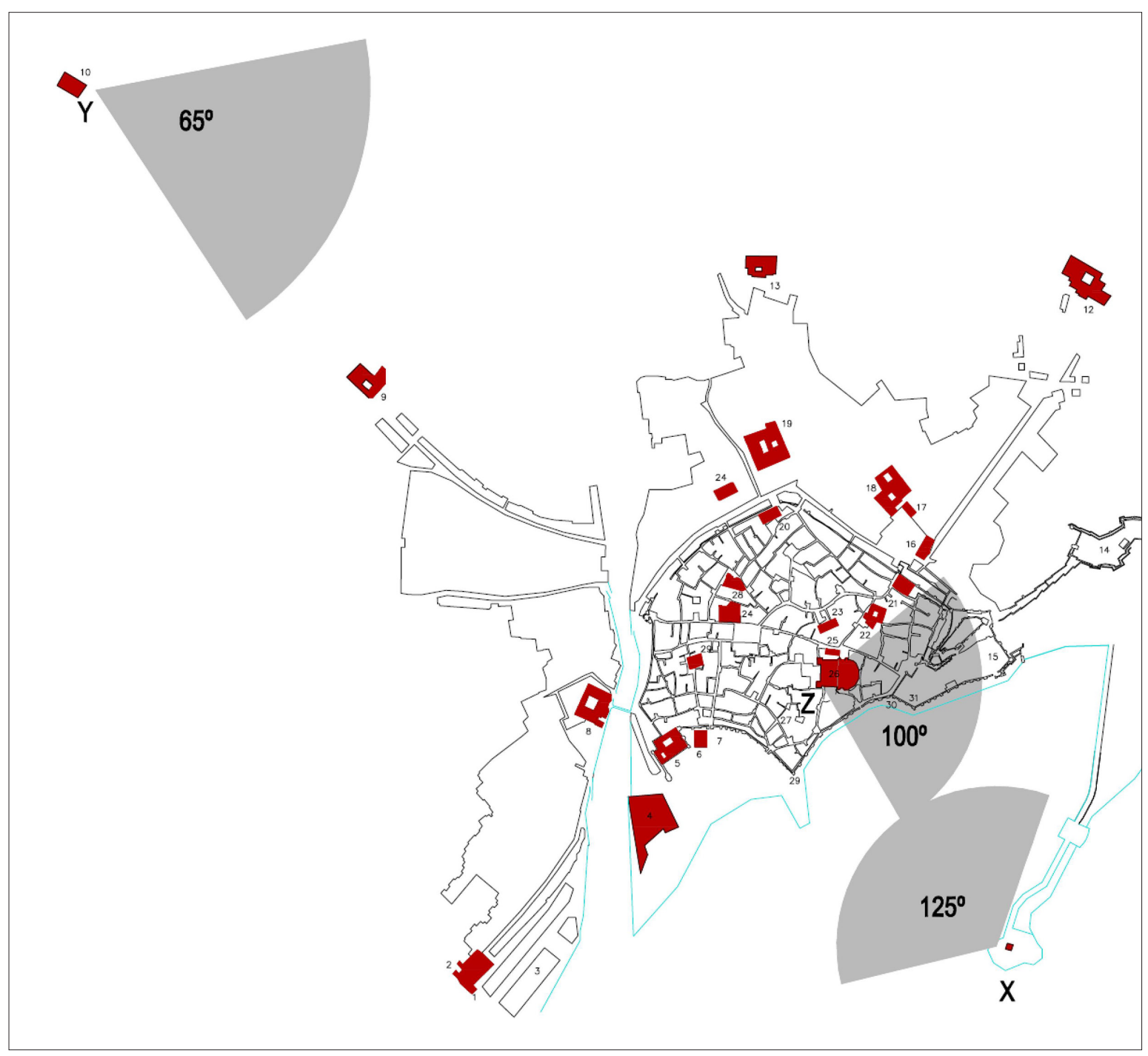

2. Plano esquemático de Málaga a finales del siglo XVIII con ubicación de puntos de vista y ángulos visuales de las panorámicas de Carter. Elaboración propia

y el puerto desde el mar; en el segundo, el punto de vista se sitúa en las inmediaciones del convento de los Ángeles, y la imagen abarca desde los cerros de San Cristóbal y Calvario hasta el convento de la Trinidad. La tercera es una vista algo más restringida hacia el muelle nuevo, dibujada desde la torre inacabada de la catedral. En todas ellas aparecen la ciudad y sus más importantes edificaciones en su territorio circundante, con las montañas o el Mediterráneo como fondo.

Para su análisis, en primer lugar se han localizado los puntos desde los que se dibujaron sobre un plano de la ciu- dad, estimando la amplitud de los conos visuales usados. De ello se deduce un claro interés por describir exhaustivamente el paisaje urbano de Málaga. Carter se situó en lugares frente a los cuales la urbe se despliega mostrando sus hitos en abanico, de forma que las torres, iglesias o conventos no quedasen superpuestos [2]. Para ello escogió dos ubicaciones opuestas: el extremo del muelle y los alrededores del convento de los Ángeles, ambos prácticamente perpendiculares a la línea divisoria de aguas del monte Gibralfaro, que además definen el eje de las dos fortalezas que sobre él se asientan. 


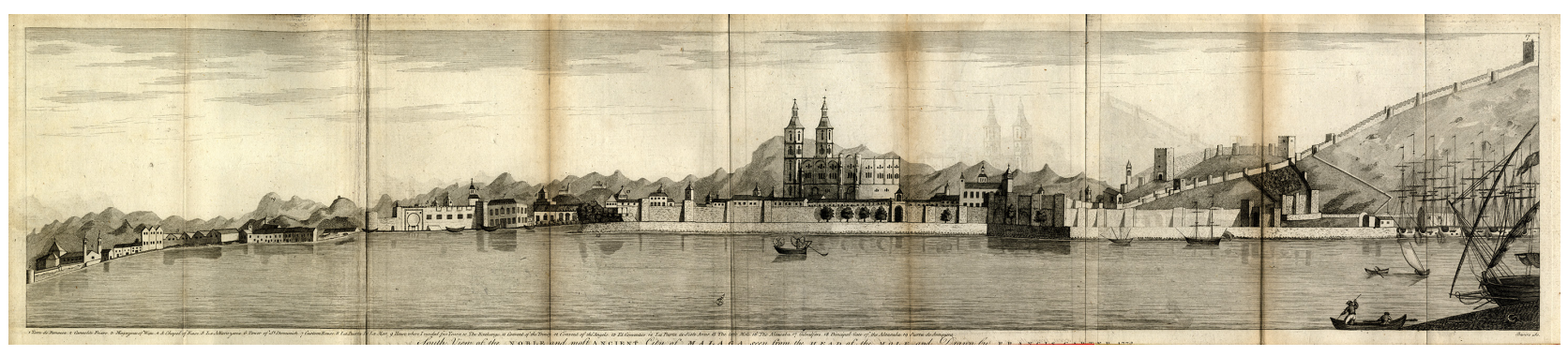

3. Francis Carter (dib., 1772) Basire (grab., 1776): South view of the noble and most ancient City of Malaga, seen from the head of the mole (colección particular)

Ello facilita la legibilidad del dibujo y favorece la identificación de los diferentes hitos urbanos y referencias topográficas. Se lograron así dos perfiles que en la práctica son casi un alzado.

El único elemento que le quedaba por describir era muy importante: el muelle, que desde el norte quedaba oculto por el caserío y desde el sur no resultaba visible por estar precisamente emplazado sobre él. Por esa razón acometió una tercera panorámica sobre la infraestructura más destacada de Málaga a efectos económicos y militares.

Además de revisar los pormenores de cada panorámica, reseñados a continuación, se ha tratado de verificar su nivel de precisión o fiabilidad, pues los grabados se realizaron a partir de los dibujos de campo con un rudimentario instrumental, según se constata en el autorretrato incluido en la vista desde el noroeste. Para ello se han usado fotografías históricas tomadas en los mismos lugares desde los que dibujó Carter, pues el paisaje urbano de Málaga está hoy muy modificado con respecto al siglo XVIII y en muchos casos los hitos dibujados por Carter han desaparecido o su visibilidad ha quedado reducida o anulada.

\section{La vista desde el mar (desde el extremo del muelle)}

La vista desde el mar [3] se encuentra en la página 341 del libro y se titula South view of the noble and most ancient City of Malaga, seen from the head of the mole. Es el más amplio de los desplegables, con una dimensión aproximada de 945 x 206 mm y nueve pliegues; los otros dos presentan dos menos. En la leyenda se incluyen abundantes e importantes referencias, indicadas a continuación:
1. Torre de Ronseca [Fonseca]; 2. Carmelite Friars; 3. Magazines of wine; 4. A Chapel of ease; 5. La Attarazana; 6. Tower of St. Dominick; 7. Custom House; 8. La Puerta de la Mar; 9. House where I resided five Years; 10. The Exchange; 11. Convent of the Trinity; 12. Convent of the Angels; 13. El Conventico; 14. La Puerta de Siete Arcos; 15. The little Mole; 16. The Alcasaba; 17. Gibralfaro; 18. Principal Gate of the Alcasaba; 19. Sierra de Antiquera.

La panorámica del conjunto urbano captada guarda similitudes con la que realizó Wyngaerde dos siglos antes, conservada en el Ashmolean Museum de Oxford (Gámiz y Ruiz, 2018), abarcando desde la Torre de Fonseca, en el extremo oeste, junto al convento del Carmen, hasta el castillo de Gibralfaro, aunque de este no se dibuja más que en un fragmento. Carter contó con la ventaja de poder situarse en el extremo del recién terminado muelle de levante, un elemento que no existía en el siglo XVI. La panorámica ofrece una amplitud inusual, equivalente a un arco de unos $120^{\circ}$, que Carter acentuó en el extremo izquierdo del dibujo de una manera algo ingenua, curvando el horizonte para acercarlo al observador, a modo de rudimentario intento de construir una perspectiva en ojo de pez.

El resultado no fue brillante desde un punto de vista artístico, pero en él se muestra una inédita fachada marítima del barrio del Perchel, incluyendo edificaciones destinadas a almacenar vinos. La imagen desordenada de este arrabal, que se había desarrollado sobre un suelo de aluvión aportado por sucesivas riadas del río Guadalmedina, contrasta con la imagen rotunda de las murallas que se asoman a la dársena. Comparando esta vista con la dibujada por 


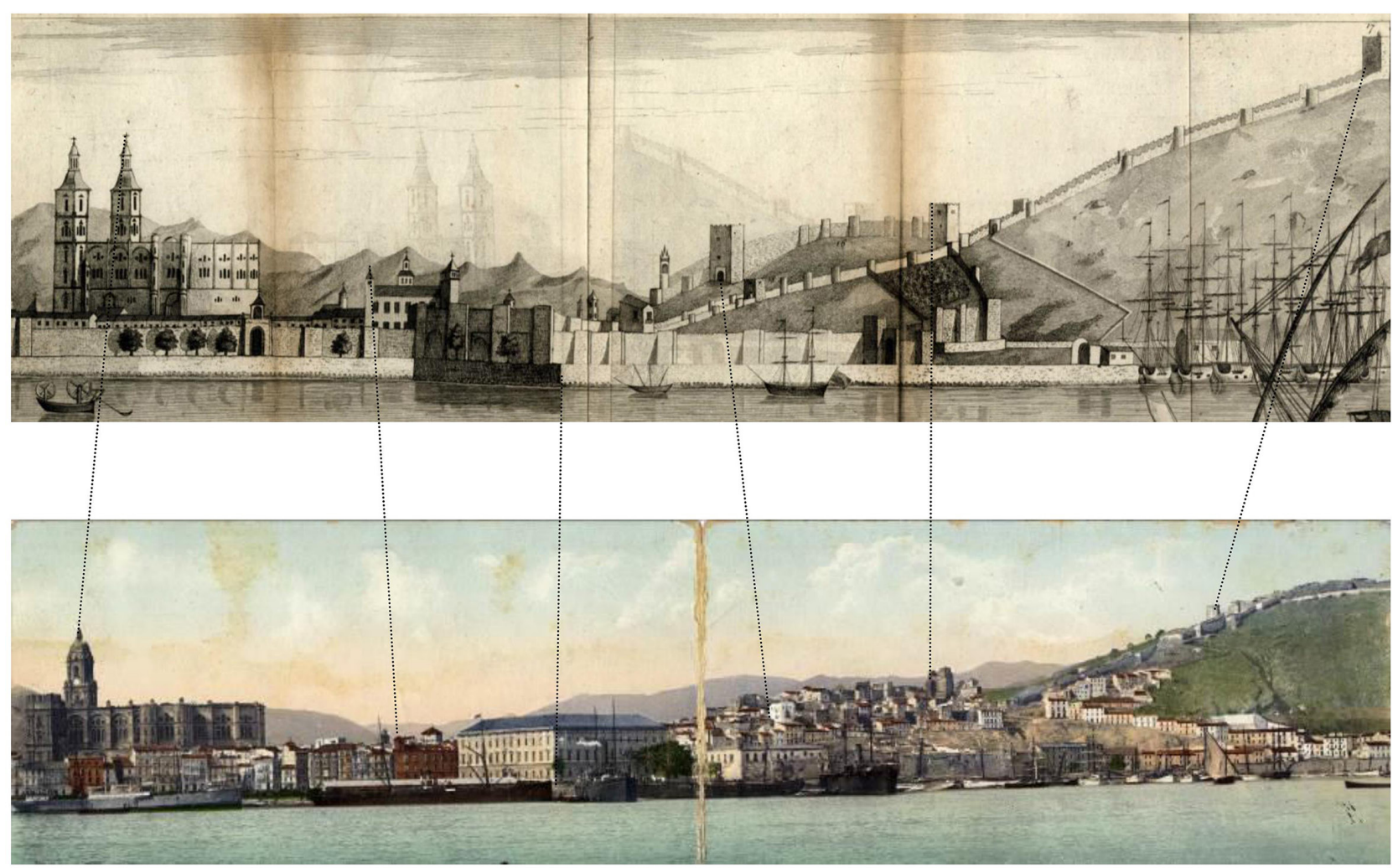

1 2 3

4

5

6

4. Correspondencias entre la vista de Carter en 1772 desde el extremo del muelle y postal con similar punto de vista editada por Purger \& Co. a principios del s. XX

Wyngaerde en 1564, se observa como novedad la aparición de los citados almacenes delante de las viviendas de pescadores que previamente habían constituido la primera línea de playa de este arrabal.

Esta vista reviste también interés por ser la última en la que aún eran visibles las murallas de la ciudad, cuya demolición estaba muy cercana (García, 1995: 171-186). El nuevo punto de vista aportado por la construcción del muelle hizo que el alzado marítimo pudiese representarse desde más hacia al Este, frente a los muros de la Alcazaba, ya que con anterioridad era la zona de la puerta del Mar la que atraía la atención de quienes querían dibujarlo. Resulta llamativo cómo Carter prescindió de su propia declaración de intenciones -en esta y otras vistas- de no dibujar cosas "que nunca existieron sino en la imaginación del grabador» (Carter, 1981: 218). En este caso, quizás traicionado por el buen ritmo que llevaban las obras de la catedral en el mo- mento de su visita, y que augurarían una pronta terminación de estas, representó ambas torres terminadas, más otros remates del templo. Como es sabido, la torre sur nunca llegó a concluirse, ni tampoco detalles como el frontón que debía coronar la fachada principal o las esculturas que rematarían los contrafuertes de las naves laterales.

En esta vista, además, Carter señaló la que fue su casa en Málaga («House where I resided Five Years»). Por su emplazamiento y características constructivas puede afirmarse que se trata del edificio que albergó las casas y almacenes del mayorazgo del marqués de Campoalegre, al exterior del tramo de muralla comprendido entre la Puerta del Mar y la de Espartería. El inmueble desapareció con la reurbanización de la zona que se produjo tras la demolición de la cerca medieval y sobre su solar se construyó el actual Pasaje Larios (Machuca, 1987: 195). Se encuentra documentado en planos conservados en el Archivo de Si- 


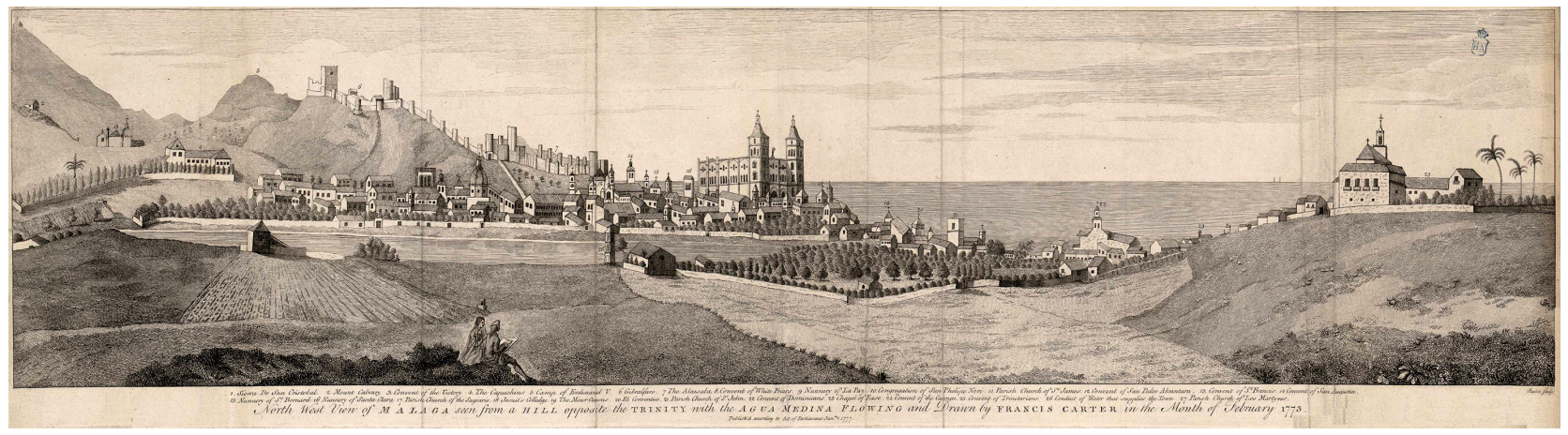

5. Francis Carter (dib., 1773) Basire (grab., 1776): North West View of Malaga seen from a hill opposite the Trinity with the Agua-Medina flowing (colección particular)

mancas (MPD, 59, 025) y en el Archivo Histórico Nacional (Consejos, n. ${ }^{\circ}$ 2311). Carter parece dibujarlo con una única altura, debido a la incipiente alameda que crecía frente a él; pero el ritmo de huecos y las proporciones de la planta alta concuerdan con documentos coetáneos y la identificación parece clara.

En el centro de la dársena aparece un pontón de cuchara que operaba en la limpieza de fondos del puerto, evidenciando los problemas de aterramiento que hubo durante el siglo XVIII (Cabrera, 1994: 208). Lo que podría considerarse como un dibujo ingenuo es en verdad una fiel representación del artilugio real, según se constata al cotejar los planos originales del mismo conservados en el Servicio Histórico Militar (B-7-37).

Esta panorámica puede compararse con una postal editada por Purger \& Co. a principios del siglo XX., cuya fotografía se tomó desde el mismo lugar [4]. A diferencia de la figura anterior, aquí las alteraciones experimentadas en el lapso transcurrido son relevantes, protagonizadas por la demolición de las murallas marítimas y la construcción de la Aduana, edificio que en lo sucesivo sería una potentísima referencia visual en la ciudad. La tarjeta postal abarca una menor amplitud que la vista de Carter, por lo que se ha seleccionado solamente la porción del grabado equivalente a esta. A pesar de las grandes transformaciones del paisaje urbano, se ha identificado una clara correspondencia entre los siguientes elementos: 1. Torre norte de la catedral; 2. Palacio de Villalcázar; 3. Punta de la Aduana; 4. Puerta de la Llave de la Alcazaba; 5. Torre del homenaje de la Alcazaba; 6. Torre albarrana de Gibralfaro.

\section{La vista desde el noroeste}

La segunda vista se titula North West View of Malaga seen from a hill opposite the Trinity with the Agua-Medina flowing [5] y mide aproximadamente $738 \times 207$ mm. El artista se autorretrató como dibujante en la parte inferior izquierda de la imagen, junto a una figura femenina. Debido a la distancia a la que se realizó el dibujo, no fue necesario un ángulo visual demasiado amplio para obtener una percepción completa de la ciudad. La leyenda incluye abundantes referencias indicadas seguidamente:

1. Sierra de San Cristobal; 2. Mount Calvary; 3. Convent of the Victory; 4. The Capuchins; 5. Camp of Ferdinand V; 6. Gibralfaro; 7. The Alcasaba; 8. Convent of White Friars; 9. Nunnery of La Paz; 10. Congregation of San Phelipe Neri; 11. Parish Church of St. James; 12. Convent of San Pedro Alcantara; 13. Convent of St. Francis; 14. Convent of San Agustin; 15. Nunnery of St. Bernard; 16. Nunnery of Santa Clara; 17. Parish Church of the Sagrario; 18. Jesuit's Colledge; 19. The Minor Canons; 20. El Conventico; 21. Parish Church of St. John; 22. Convent of Dominicans: 23. Chapel of Ease; 24. Convent of the Carmen; 25. Convent of Trinitarians; 26. Conduit of water that supplies the Town; 27. Parish Church of Los Martyres.

Por tanto quedaron representados los más importantes hitos de la silueta urbana, pero también son relevantes los datos aportados respecto a las plantaciones y vegetación existentes. A las bien documentadas huertas con fruta- 


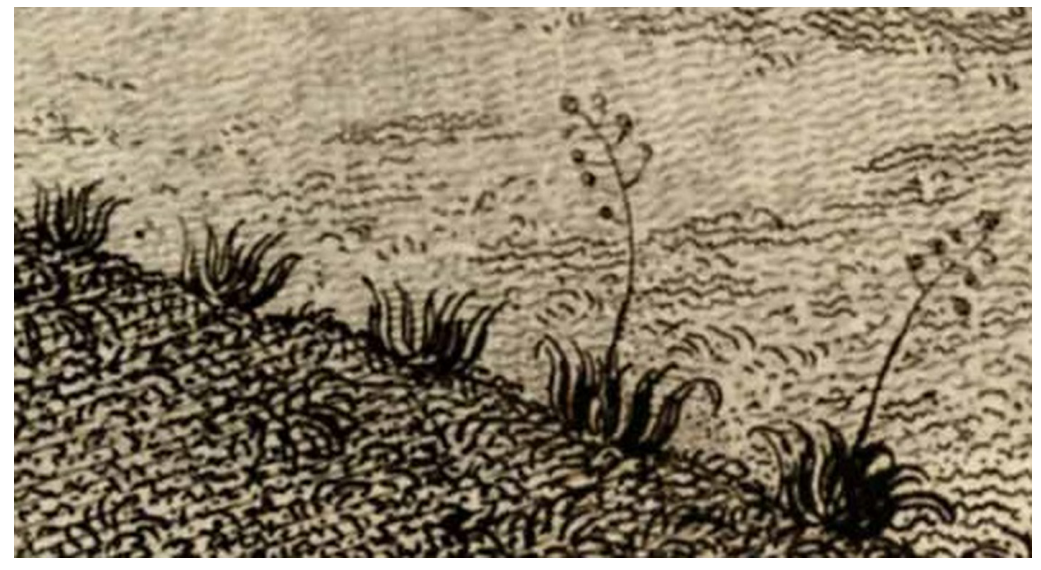

6. Francis Carter (dib., 1773) Basire (grab., 1776): North West View of Malaga seen from a hill opposite the Trinity with the Agua-Medina flowing (detalle). Autorretrato. Agave americana usada como cerramiento de parcela (detalle) les situadas en los arrabales históricos, como la Trinidad o la Fontanella, se añade información como los surcos del arado en terrenos contiguos a la ciudad, indicio de cultivos de temporada, y la presencia de palmeras o cipreses en conventos (en la Trinidad y en Capuchinos, respectivamente) y un uso temprano del agave o pita a modo de cerramiento de parcela [6]. En el texto se alude también a los abundantes viñedos y olivares existentes en los alrededores de Málaga (Carter, 1981: 321-325).

La vista dibujada por Carter desde las inmediaciones del convento de los Ángeles puede compararse con la fotografía tomada por Charles Clifford en 1860, prácticamente desde el mismo punto de vista [7]. La diferencia más apreciable entre ambas imágenes es que en la fotografía ya se ha formalizado la orilla este del Guadalmedina, lo que aún no había sucedido en el siglo XVIII.

Clifford abarcó una menor amplitud que Carter, por lo que se ha comparado solo la porción del grabado equivalente a la fotografía. A pesar de la ingenuidad en el grafismo con que Carter representa los hitos del paisaje y los edificios -que además aparecen estilizados, quizás con el propósito de realzarlos visualmente- estos se distribuyen en el paisaje con un rigor y una meticulosidad que contradicen la primera impresión. Se ha constatado una clara correspondencia en los siguientes elementos de ambas vistas: 1. Torre albarrana de Gibralfaro; 2. Congregación de San Felipe Neri; 3. Torre del homenaje de la Alcazaba; 4. Alcubilla de Martiricos; 5. Convento de San Agustín; 6. Convento de Santa Clara; 7. Catedral; 8. Jesuitas; 9. Parroquia de San Juan.

\section{La vista desde la torre sur de la catedral}

La vista realizada desde la torre inacabada de la catedral hacia el muelle se titula West view of the Mole of Malaga seen from one of the towers of the Cathedral [8] y mide aproximadamente $718 \times 206 \mathrm{~mm}$. Ofrece una perspectiva inusual de la fachada meridional del templo renacentista, parcialmente visible en la parte izquierda del grabado. Detrás aparece el conjunto Alcazaba-Gibralfaro, en su silueta característica que comprende el monte san Cristóbal a la izquierda, y a la derecha el perfil de la costa hacia levante. Perpendicular a dicha costa y con carácter de alzado, la cara interna del muelle recién terminado ocupa más de la mitad del papel. En el centro del dique destaca la capilla portuaria, adosada a la batería de San Nicolás, que estaba orientada hacia mar abierto y aquí muestra su cara trasera. En el extremo, se aprecia la linterna sustituida en 1817 por la actual Farola.

La escena se anima con diversas naves que están al abrigo del dique: en el tramo más cercano a tierra firme, varias embarcaciones menores en el espacio de la dársena de menor calado; más alejadas se detallan cuatro de mayor porte. Uno es un jabeque y los otros tres (dos de ellos abarloados) son navíos ingleses, a los que Carter no olvida colocar la Red Ensign a popa, bandera distintiva de la condición mercante del buque. Dichos datos aportan claros indicios sobre el carácter y el uso de las instalaciones portuarias en la época, pues esa es sin duda la principal finalidad de esta tercera vista en la que el casco urbano está ausente en buena parte, pues ya había sido descrito en las otras dos vistas. De hecho, 


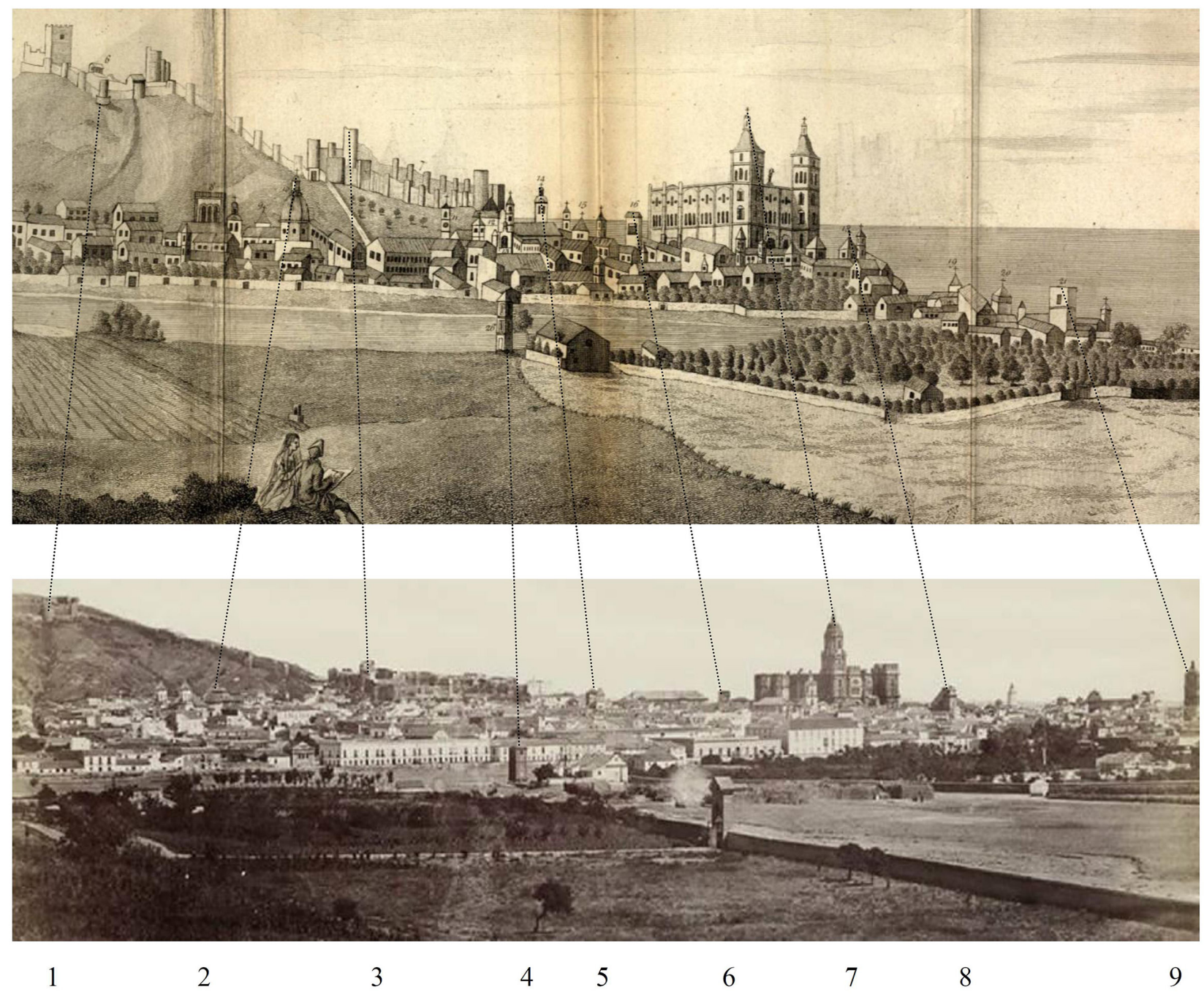

7. Correspondencias entre la vista dibujada por Carter en 1773 desde el noroeste y la fotografía tomada desde similar punto de vista por Charles Clifford hacia 1860

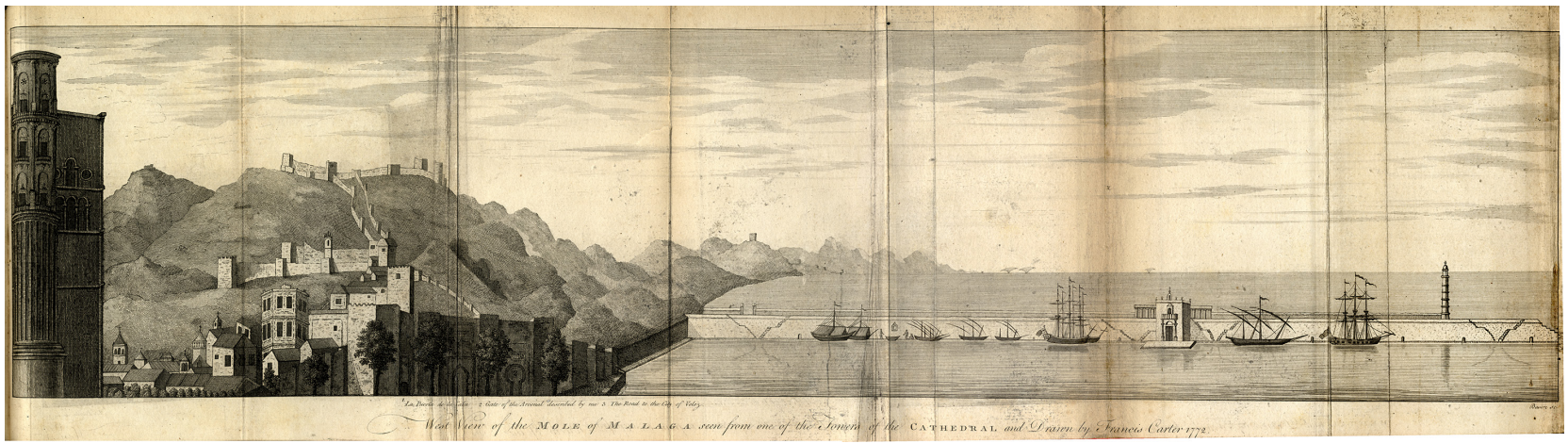

8. Francis Carter (dib., 1772) Basire (grab., 1776): West view of the Mole of Malaga seen from one of the towers of the Cathedral (colección particular) 


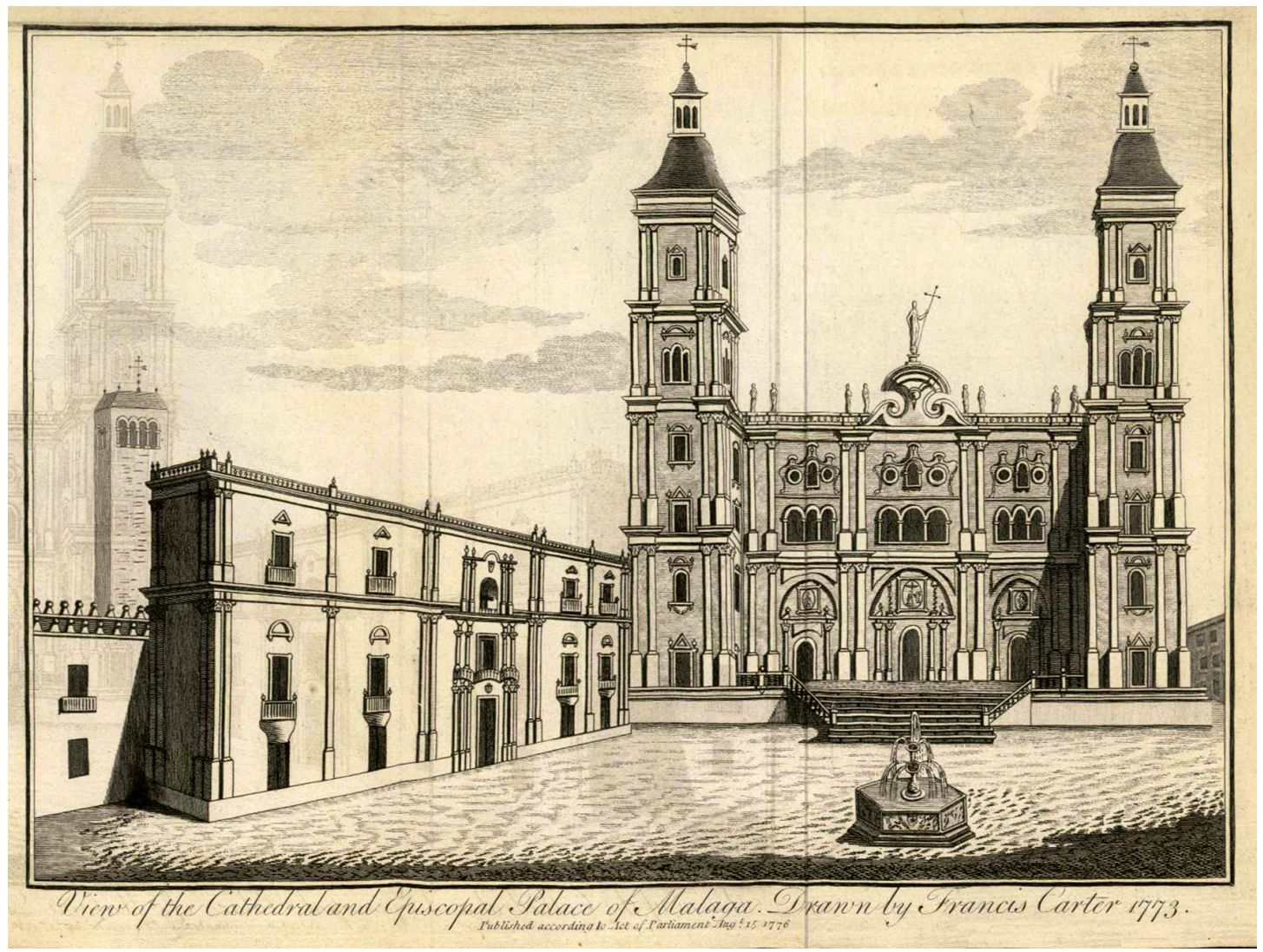

9. Francis Carter (dib., 1773) Basire (grab., 1776): View of the Cathedral and Episcopal Palace of Malaga (colección particular)

Carter etiquetó muy pocos elementos en la leyenda de esta tercera imagen: 1. La Puerta de la Caba. 2. Gate of the Arcenal described by me; 3. The Road to the City of Velez. O sea, tan sólo dos puertas en el antiguo corral bajo de la Alcazaba, las de la Caba y del Arsenal y el camino de Vélez. Ambas desaparecerían poco después para dejar expedito el solar en el que se habría de construir la nueva Aduana, un detalle del mayor interés documental. En todo caso debe destacarse la originalidad del punto de vista de esta panorámica, pues no se han podido localizar otras imágenes históricas de cierto interés tomadas desde el mismo lugar.

\section{Otras ilustraciones}

El libro incluye un cuarto desplegable en el que se representan los dos principales edificios de la plaza del Obispo: el palacio del mismo nombre y la catedral [9]. Sin embargo, Carter no considera esta lámina en la misma categoría que las otras tres, quizás por ser una vista urbana parcial. En el centro de ella aparece la fuente que aún hoy preside este espacio. La escena permanece casi idéntica en la actualidad, salvo el ya citado detalle de que la catedral aparece con la segunda torre y remates completados.

Además, entre el texto se insertaron otras ilustraciones con detalles arquitectónicos y restos arqueológicos. Junto a ciertas inscripciones de origen romano, cuatro de ellas se centran en edificios islámicos: la puerta de la Llave (o de la Justicia) de la Alcazaba, uno de los escudos que flanquean la portada principal de las Atarazanas, el mosaico existente en la bóveda del acceso al castillo de Gibralfaro y una de las tres puertas del arsenal de la Alcazaba.

Salvo este último elemento, los otros tres han llegado hasta nuestros días, aunque la puerta de la Llave está 
desprovista de toda la ornamentación incluida en el dibujo de Carter, que se sorprendió por la conservación de aquellos ladrillos esmaltados en distintos colores antes de que hubiesen sido arrancados violentamente de su sitio (Carter, 1981: 290).

Además reviste especial interés el alzado de la puerta del arsenal de la Alcazaba, cuya descripción escrita se complementa con los datos gráficos aportados por la vista desde la torre de la catedral. Carter añadió incluso una escala gráfica en pies para dar idea de las dimensiones. El conjunto compuesto por esta puerta y las dos que la acompañaban, debían de tener una presencia imponente en el frente marítimo de Málaga, pues su altura doblaba la de las murallas del resto de la fortificación y presentaba una orientación distinta al resto del lienzo de murallas que miraba al mar. Sobre la ornamentación de sus arcos, en los que Carter aún detecta marcas de las bisagras de unas hojas de madera que ya no existían, decía que «a pesar de ser tan próximos y de la misma altura, no se parecen en nada» e indicaba que «consiste en una especie de rectángulo o rombo, elevado sobre las paredes por dos ladrillos, colocados de lado a unos tres pulgadas de la superficie» (Carter, 1981: 290), es decir, un patrón de sebka islámica.

\section{Conclusiones}

La ciudad de Málaga cuenta con abundantes vistas que ilustran diversas etapas de su paisaje pretérito. Entre ellas, las panorámicas dibujadas por Francis Carter han sido hasta ahora objeto de escasa atención, quizás debido a una cierta ingenuidad de su grafismo y a su aparente falta de fiabilidad topográfica, considerándose como una mera ilustración o acompañamiento de su conocido texto.

Las vistas de Carter pueden encuadrarse dentro de una vieja tradición de imágenes descriptivas de países, regiones o provincias, en las que se identificaban visualmente sus principales hitos. La esquemática técnica lineal resultó bastante apropiada para representar los contornos de las formas urbanas y paisajísticas descritas, aunque su calidad gráfica fue superada por otras muchas vistas de Málaga en el siglo XIX, debidas a destacados autores como David Roberts, George Vivian u otros.

Hay que recordar que Carter no fue exactamente un viajero, según sugiere el título de su libro, y que sus minuciosas observaciones vienen avaladas por su condición de residente en Málaga durante largo tiempo, con los beneficios que ello supuso para una minuciosa compilación de datos y para la elección de puntos de vista de manera concienzuda. Tampoco debe olvidarse que el objetivo de los dibujos, según expresó el propio Carter en su obra, era recopilar una información exhaustiva y rigurosa. Sus fines eran preferentemente didácticos y documentales, antes que estéticos. No se trata de vistas con un gran valor artístico, pero el cumplimiento de sus propósitos queda sobradamente avalado al haberse revisado la detallada información incluida en las vistas, usando otras vistas como referente comparativo.

Las tres panorámicas sobre Málaga no solo retratan con fiabilidad su paisaje urbano en cuanto a hitos arquitectónicos y relaciones visuales existentes entre ellos. Además aportan abundante información sobre cuestiones sutiles que no aparecen reflejadas en las imágenes de otros autores, como el comercio marítimo, los cultivos u otros muchos pormenores del mayor interés.

\section{Bibliografía}

CABRERA PABLOS, Francisco R. (1994), Puerto de Málaga. De Felipe V a Carlos III, Servicio de Publicaciones de la Autoridad Portuaria de Málaga, Málaga.

CARTER, Francis (1777), A Journey from Gibraltar to Malaga, with a View of that Garrison and its Environs; a Particular Account of the Towns in the Hoya of Malaga; the Ancient and Natural History of those Cities, of the Coast between them, and of the Mountains of Ronda. Illustrated with the Medals of each Municipal Town; and a chart, perspectives and drawings, taken in the year 1772, T. Cadell, Londres. - (1981), Viaje de Gibraltar a Málaga, Servicio de Publicaciones, Diputación Provincial de Málaga, Málaga.

GÁMIZ GORDO, Antonio (2011), «Vistas de ciudades andaluzas hasta mediados del siglo XIX», Revista ph, n. ${ }^{\circ}$ 77, febrero, pp. 74-79. 
GÁMIZ GORDO, Antonio y RUIZ PADRÓN, Luis (2018), «The First Views of Malaga in the 16th Century: Graphic Sources for Research», en Architectural Draughtsmanship, Springer, Cham, pp. 1325-1337. https://doi.org/10.1007/978-3-319-58856-8_104.

GARCÍA GÓMEZ, Francisco (1995), «La frontera sur de Málaga. Evolución de la muralla desde el castillo de san Lorenzo hasta la puerta de los Siete Arcos», Boletín de Arte, n. ${ }^{\circ} 16$, pp. 171-186.

GARVAYO GARCÍA, Dolores (2003), “¿Status de residente? Nuevas aportaciones biográficas del viajero inglés Francis Carter», en VILLAR GARCÍA, María Begoña y PEZZI CRISTÓBAL, Pilar (eds.): Los extranjeros en la España moderna. Actas del II coloquio internacional, Málaga, pp. 307-321.

MACHUCA SANTA-CRUZ, Luis (1987), Málaga, ciudad abierta. Origen, cambio y permanencia de una estructura urbana, Colegio de Arquitectos, Málaga.

MARÍAS, Fernando (2002), «Imágenes de ciudades españolas: de las convenciones cartográficas a la corografía urbana», en MARÍAS, Fernando y PEREDA, Felipe (eds.), El Atlas del Rey Planeta. La «Descripción de España y de las costas y puertos de sus reinos» de Pedro Texeira (1634), Editorial Nerea, Hondarribia, pp. 99-116.

OLMEDO LÓPEZ, José Antonio (1980), «El viaje de Gibraltar a Málaga de Francis Carter», Jábega, n. 32, pp. 38-41.

RUIZ PADRÓN, Luis (2016), Málaga, dibujos de ciudad y paisaje hasta 1850, tesis doctoral inédita (dir. A. Gámiz Gordo), Universidad de Sevilla. 